\title{
The Effects of Corruption in Entrepreneurial Ecosystems on Entrepreneurial Intentions
}

\author{
Francesco Ceresia $^{*}+\boldsymbol{+}\left(\mathbb{D}\right.$ and Claudio Mendola ${ }^{\dagger}$ \\ Department of Political Science and International Relations, University of Palermo, 90134 Palermo PA, Italy; \\ mendola.claudio@gmail.com \\ * Correspondence: francesco.ceresia@unipa.it; Tel.: +39-339-232-4611 \\ + These authors contributed equally to this work.
}

Received: 30 September 2019; Accepted: 13 November 2019; Published: 16 November 2019

\begin{abstract}
Although researchers have identified corruption as a factor capable of affecting the entrepreneurial ecosystem at the national level of analysis, scholars have reported conflicting results regarding the exact nature of the relationship between corruption and entrepreneurial intentions. This paper formulates some propositions about the complex relationship between corruption and entrepreneurship at different levels of analysis and it suggests and explores the socio-cultural consequences of such domains' interactions. Finally, the slippery-slope effect will be discussed as an intra-individual psychological mechanism that could explain why even morally-engaged people might replicate corrupt behaviors. The limitations of this work, and its implications for future researchers and for government policies will be analyzed.
\end{abstract}

Keywords: corruption; perceived corruption; entrepreneurial intention; entrepreneurial ecosystem; entrepreneurial development

\section{Introduction}

Scholars' growing interest in undercovering the antecedents of entrepreneurial intention is due to the large and decisive contribution that entrepreneurship has proven to provide to a country's economic development (Aidis et al. 2012; Aparicio et al. 2016; Engle et al. 2010; Holcombe 1998; Lucas and Fuller 2017; Samila and Sorenson 2011; Wennekers and Thurik 1999; Bell 2019). The processes and characteristics of a country that are capable of influencing business activities, entrepreneurial intentions and economic development are what North (1991) refers to by the term institutions. These institutions have been divided into two main categories: formal and informal factors. The former refer to the norms and regulations individuals must follow in order to start and manage a firm. The latter refer to people's beliefs, their shared social norms and their perceptions of characteristics of the entrepreneurial ecosystem in which they act and through which the formal factors are perceived, and consequently, adopted (North 1991, 2005; Aparicio et al. 2016; Neneh 2014; Stenholm et al. 2013).

However, Urbano and Alvarez (2014), taking into account the model originally developed by Scott (1995) and Orr and Scott (2008), and applying it to the entrepreneurial field of study, have reorganized these institutions into three different dimensions:

- The regulative dimension, linked to the laws, rules, norms and government policies that aim to support new firms by reducing the economic risks associated with start-ups and helping entrepreneurs to obtain credit.

- The normative dimension, that refers to culturally shared values regarding the importance of entrepreneurship and being an entrepreneur, and having personal qualities linked to the entrepreneurial field, such as creativity and divergent thinking. 
- The cognitive-cultural dimension, that encompasses an individual's feelings about the extent to which they possess the knowledge and skills required to start and manage a firm and his/her attitudes and perceptions towards entrepreneurship.

The model adopted by Urbano and Alvarez (2014) actually seems rather similar to the one proposed by North $(1991,2005)$, since the regulative dimension appears to mirror the formal factors, whereas the normative and cultural-cognitive dimensions correspond to the informal ones. However, Urbano and Alvarez (2014) pointed out that the informal factors should be split into two main dimensions in accordance with their effects on entrepreneurial intention and economic development, respectively, at the country and the individual levels of analysis. They proposed splitting the informal factors into the normative and cognitive-cultural dimensions, since the former refer to the culturally-shared considerations and aspects that might affect entrepreneurship on a national level, such as the percentage of people in a country that attach high status to successful entrepreneurs (Urbano and Alvarez 2014, p. 709), or on an individual level, such as personal attitudes towards entrepreneurship or individual entrepreneurial self-efficacy (Drnovšek et al. 2010; Scott 1995; Urbano and Alvarez 2014; Esfandiar et al. 2019).

Moreover, in the last few decades, the idea that the development of entrepreneurship within a country can be affected by dimensions linked to individuals' characteristics, cultural shared values and the systems of laws and norms that regulate the firm managing process has brought to life the concept of entrepreneurial ecosystems (EE) (Singh et al. 2019; Alvedalen and Boschma 2017; Acs et al. 2017; Stam and Spigel 2016). This peculiar term—ecosystem-has been borrowed from other sciences-as a metaphor-to represent a system composed of several parts, strictly interconnected. (Kuckertz 2019). Although a common shared definition of EE is yet to be found (Faggian et al. 2017), we share the one proposed by Stam in his works, "A set of interdependent actors and factors coordinated in such a way that they enable productive entrepreneurship within a particular territory" (Stam 2018; Shwetzer et al. 2019). Stam $(2015,2018)$, taking hints from the pioneering work of North (1991) and the literature on the topic, provided a rather complete description of the factors that can, together, affect entrepreneurship. He, therefore, made a distinction between framework conditions (formal institutions, informal institutions (e.g., entrepreneurial culture), demands for new goods and physical infrastructure) that are linked to the value creation process within EE, and systemic conditions (networks of entrepreneurs, leadership, finance, talent, knowledge and support services) that are specifically connected to the start-up process (Stam 2015, 2018; Brown and Mawson 2019). Despite the distinctions briefly reported, the factors are intended to interact among themselves (Stam 2018; Singh et al. 2019) and create aggregate value through virtuous circles (Faggian et al. 2017), as interaction is a key, core element of the entrepreneurial ecosystem model. It must be specified, however, that EEs are country-related, since they are specifically linked to contextual characteristics that can differ from region to region (Szerb et al. 2019). For the scope of this paper, we will go deeply in the framework conditions as they encompass the level of perception of corruption within a country (as a formal institution) and the informal factors, such as how much being an entrepreneur is valued (as an informal institution).

Using as our starting point the evidence in the literature that seems to indicate that institutions have different effects at different levels of analysis (Scott 1995; Urbano and Alvarez 2014), this work provides a review of the possible effects of corruption on entrepreneurship at both the individual and national level of analysis. In that sense, we tried to answer the question: are the effects of corruption on individuals' entrepreneurial intentions never changing and context-free?

Moreover, we introduce the importance of perceptions in shaping actual individual behaviors, by discussing a series of propositions about the ways perceptions of corruption could affect entrepreneurial intention (Engle et al. 2010; Linan and Chen 2009) and how even honest people may end up behaving corruptly. In this sense, this paper hints at the support that a psychological perspective may give to the literature about corrupt behaviors in entrepreneurial ecosystems. 


\section{The Institutional Dimension and Entrepreneurial Intentions}

\subsection{Entrepreneurial Intentions and Entrepreneurship}

Many scholars have identified entrepreneurship as an example of a planned behavior highly characterized by intentionality (Engle et al. 2010; Ceresia 2018; Arranz et al. 2019; Wang et al. 2019), since it can be considered a career choice. Behavioral intentions, defined as states of mind that direct the attention and effort of a person towards specific goals, are regarded as the most powerful precursor of planned behavior (Ajzen 1991). From this consideration, we can argue that intentions towards the creation and managing of a firm can be considered a valid antecedent of entrepreneurial behavior. As the literature on the topic reports, entrepreneurial individuals' intentions can be affected by factors related both to the inner psychological worlds of the individuals and to the external social, bureaucratic and economic situation of a country (Ajzen 1991; Neneh 2014; Gilmartin et al. 2019); thus, making it a suitable variable to intercept the effect of macro phenomena-such as corruption-on individuals' behaviors-e.g., starting a new firm - and vice versa. In the light of this consideration, we will now discuss the factors capable of hindering or fostering entrepreneurial intentions.

\subsection{A Differential Analysis of the Effects of Institutional Dimensions on Entrepreneurial Intentions}

Several scholars have underlined how the normative and cognitive-cultural dimensions have a greater impact on business activity, economic development and entrepreneurial intentions than the regulative dimension (Aparicio et al. 2016; Thornton et al. 2011).

Urbano and Alvarez (2014), aiming to uncover the effects of the three institutional dimensions on the entrepreneurial ecosystem, demonstrated how entrepreneurial intentions are more influenced by the cognitive-cultural dimension-rendered operational through the measurement of entrepreneurial skills, the fear of failure and any direct familiarity with an entrepreneur-than the regulative one. Taking into account this result, we may suppose that factors which are directly linked to the inner psychological world (psychological-cognitive variables)—such as perceptions and beliefs about oneself or the entrepreneurial ecosystem-might have a greater impact on fostering EI than variables linked to the outside world-such as the presence of norms and rules—even if strict. Aparicio et al. (2016) seems to go in that direction as well and prove that one's individual perception of governmental efforts to stop corruption and one's beliefs about one's own entrepreneurial skills and knowledge can affect entrepreneurial intentions more than norms and government policies. Moreover, the study of Choo and Wong (2006), meant to explore the importance attributed to factors capable of fostering or hindering the entrepreneurial careers and intentions of would-be entrepreneurs, seems to go in that direction as well. In fact, they found that the difficulties associated with personal capabilities (perception about lack of skills) and the perceptions of economic risk and future uncertainty (hard reality) ranked higher than the difficulties linked to being bound by entrepreneurial rules (compliance costs) (Choo and Wong 2006).

Such results could be explained by taking into account the fact that everyone tends to maintain a state of cognitive equilibrium between perceptions, attitudes, beliefs and behaviors (Heider 1946). In accordance with the self-verification theory, the choice of becoming an entrepreneur may be seen mainly to be a way for individuals to verify themselves and their own beliefs (Swann 1983). Only after their intentions pass the self-verification process do would-be entrepreneurs come to terms with the limitations posed by the real socio-economic and cultural context in which they live, such as regulations and norms relating to credit access. In other words, it is primarily through beliefs, social norms and self-efficacy perceptions - the informal factors that one wants to self-verify with-that individuals define their own career aspirations and paths, by attributing meaning to stimuli from the external world (Urbano and Alvarez 2014). The decision to launch a start-up is mainly based on what would-be entrepreneurs perceive as desirable for themselves, what is feasible based on their internal and external resources and what is ethically acceptable. Only after these conditions are met, would-be entrepreneurs 
tend to come to terms with the regulative dimension in order to achieve their career goals (Autio et al. 2001; Engle et al. 2010; Linan and Chen 2009).

\section{Corruption and Entrepreneurial Intentions}

The impact of corruption on entrepreneurial dynamics became an attractive topic for scholars after the appearance of public scandals that led to the delegitimization of many governments in the last 40 years (Husted 1999). Corruption could be defined as the illicit use of one's position or power for perceived personal or collective gain (Ashforth et al. 2008, p. 671).

Several scholars have demonstrated that corruption has significant effects on the entrepreneurial ecosystem and economic development of a country (Moiseev and Goncharova 2019; Zakharov 2019; Bardhan 1997; Mauro 1995). More recently, scholars have underlined that people's perceptions about corruption and the efficacy of governmental efforts to fight corruption are important elements of their cognitive-cultural dimension and have been greatly underestimated as influences of peoples' entrepreneurial intentions (Aparicio et al. 2016; Neneh 2014; North 1991; Stenholm et al. 2013).

In literature, corruption and corrupt behaviors have been studied through different methods, taking into account micro (as individual phenomenon) and macro (as country-level phenomenon) points of view (Pertiwi 2018). First of all, on an individual level, corrupt behaviors have been tested inside experiments-e.g., business and trust games-within laboratories and controlled environments-settings where scholars investigated the factors capable of making individuals act corruptly. (Armantier and Boly 2008; Barr and Serra 2010). For example, Barr and Serra (2010) reported how corrupt behaviors can be predicted taking into account the pervasiveness of corruption within the countries where the subjects came from. More specifically, undergraduate subjects coming from highly corrupt countries were more likely to act corruptly than graduated subjects coming from the same countries. This astonishing result led the scholars to propose that corruption might be identified as a cultural phenomenon able to influence people's ideas and behaviors (Barr and Serra 2010). However, the experimental approach to corruption has two possible flaws: One linked specifically to the illegal nature of corrupt behaviors; people might avoid behaving corruptly in fear of being discovered or being seen as someone who justify corruption (Johnson and Van de Vijver 2003; Andersen and Mayerl 2017; Moreno 2002). The other one is connected to the fact that laboratories cannot fully duplicate natural environments; thus, this approach may suffer from weak external validity (Levitt and List 2007; Barr and Serra 2010).

For these reasons in the literature, corruption has been studied mostly by means of indicators elaborated by global organizations that analyze the perception of corruption at a national level of analysis (Jancsics 2019). For example, the corruption perception index (CPI), which represents the perception of the pervasiveness of corruption, and the control of corruption index (CC), which measures the perception of the efficacy of governmental efforts to fight corruption, are the indexes used most in the literature on the topic (World Bank 2016; Transparency International 2017). Though they are indicators of simple perceptions, the CPI and CC are considered by scholars as valid and reliable tools to assess the real presence of corruption in a specific socio-economic context and the efficacy of government policies that aim to eradicate corruption (Olken 2009). This shared consideration is rooted in the fact that the corrupt activities are managed and carried out in a covert way, making it almost impossible for researchers to have objective and reliable data about their occurrences within a country-wide entrepreneurial ecosystem.

There are several studies that have extensively explored the possible effects of corruption on a national economy and entrepreneurial development at a national level of analysis, although their results have often been in contrast (del Mar Salinas-Jiménez and Salinas-Jiménez 2007; Dutta and Sobel 2016; Paunov 2016; Dreher and Gassebner 2013; Hanoteau and Vial 2014; Anokhin and Schulze 2009; Glaeser and Saks 2006; Li and Wu 2010). On the other hand, it is quite rare to find studies aimed at uncovering the possible effects of corruption on entrepreneurial behaviors and intentions at an individual level of analysis. 


\subsection{The Effects of Corruption on Entrepreneurial Intentions: The National Level of Analysis}

The literature about the effects of corruption on entrepreneurial intentions at a national level of analysis presents two opposite hypotheses: the grease-the-wheel and the sand-the-wheel hypotheses.

The supporters of the grease-the-wheel hypothesis believe that in countries characterized by numerous barriers to entrepreneurial activity, such as excessively strict norms and regulations or obstacles to obtaining credit, corruption may play the role of an economic catalyst. In fact, it can foster the creation of new firms by helping people to overcome bureaucratic limitations by simplifying-through illicit means-business procedures and processes (Dreher and Gassebner 2013; Hanoteau and Vial 2014). Harbi and Anderson (2010), by using an econometric model, underlined that when the perceived corruption index increases (i.e., the economy is seen as corruption-free) the self-employment rate decreases.

On the contrary, supporters of the sand-the-wheel hypothesis firmly exclude corruption as a phenomenon that may have positive effects on entrepreneurial development. This consideration finds its reasons due to the terrible consequences that corruption has on the competitiveness of the productive system, the problems associated with copyright and patent grants, and the obstacles encountered by firms seeking to enter the market (Dutta and Sobel 2016; Hanoteau and Vial 2014; Mauro 1995; del Mar Salinas-Jiménez and Salinas-Jiménez 2007; Gang and Yano 2017).

Although these two hypotheses seem incompatible, Hanoteau and Vial (2014) proposed that they could perhaps coexist within the same entrepreneurial ecosystem, arguing that corruption may affect a company's bottom line differently according to a few specific, contextual factors. For example, Zhou and Peng (2012) showed that corruption and bribery could generate more advantages for big firms than for small and medium-sized firms, due to the greater financial resources of the former. As Hanoteau and Vial (2014, p. 1) suggested: we argue that the grease and sand-the-wheel effects are likely to co-exist among a large number of firms, and that the industrial effect of corruption depends on the productivity drivers that fuel a firm's dynamics.

In light of these considerations, a growing number of researchers are wondering whether the effect of corruption on entrepreneurial behavior is specific to the context in which entrepreneurs act. Ward et al. (2019) and Harbi and Anderson (2010) underlined that when the perceived corruption index increases, the number of patented innovations increases, too. Since patent grants are a proxy of innovative (effective) entrepreneurship, it could be hypothesized that the positive impact of corruption on entrepreneurial development is limited to the start-up birth rate, but has a negative impact on a ability of firm's ability to generate innovations and sustainable competitive advantages.

Taking into account those considerations, we formulated the following proposition:

Proposition 1. Corruption generally exerts a negative effect on entrepreneurial intentions at a national level of analysis, whereas this effect is negatively moderated by the number of restrictions placed on entrepreneurial activity by institutional dimensions.

\subsection{The Effects of Corruption on Entrepreneurial Intentions: The Individual Level of Analysis}

Studies focused on the effects of the corruption of an entrepreneurial ecosystem on entrepreneurial intentions have reported conflicting results. Allini et al. (2017) underlined that Italian college business students' entrepreneurial intentions are negatively predicted by the perception of the pervasiveness of corruption in the entrepreneurial ecosystem, since it produces a climate of distrust (Ciziceno and Travaglino 2019) and a perceived reduction in the probability of business success. This study seems to confirm the sand-the-wheel hypothesis.

Nevertheless, Djankov et al. (2005) in a study aimed at identifying the characteristics of Russian entrepreneurs that distinguish them from the rest of Russian citizens, demonstrated that entrepreneurs tend to be more inclined to justify corruption. From this perspective, corruption is viewed by entrepreneurs as an effective strategy to solve business processes, in accordance with the grease-the-wheel hypothesis. 
Some scholars have shown that corruption perception is a positive antecedent of entrepreneurial intentions in a sample of Italian college students and graduates, supporting the grease-the-wheel hypothesis (Ceresia and Mendola 2019). In line with the studies cited earlier, Neneh (2014) also observed a positive, but weak, correlation between exogenous obstacles-a variable referring to bribery, corruption and crime-and young Cameroon college students' entrepreneurial intentions.

Such results seem to confirm-indirectly and at an individual level of analysis - the hypothesis formulated by Harbi and Anderson (2010) regarding the role of corruption as a grease-the-wheel factor affecting entrepreneurial intentions. The only exception contrasting this hypothesis is represented by the work of Allini et al. (2017), which displays a negative relationship between corruption and entrepreneurial intentions.

First of all, it is important to underline that all of the studies that have reported a positive relation between corruption and entrepreneurial intentions have been carried out in countries characterized by a high level of corruption at the national level. This could support the hypothesis proposed by Djankov et al. (2005) that entrepreneurs, working on daily basis in an entrepreneurial ecosystem with a high degree corruption, are inclined to learn, signify and assimilate corruption and corrupt behaviors as part of their ordinary managerial activities. In other words, having acquired specific skills and competencies - culturally transmitted-about planning, implementing and monitoring corrupt behaviors, entrepreneurs might end up perceiving these activities as acceptable behaviors, useful to avoiding uncertainty and lowering entrepreneurial risks (Hanoteau and Vial 2014; Harbi and Anderson 2010; Ceresia and Mendola 2019).

Hence, it seems that entrepreneurs and even young, would-be entrepreneurs operating within socio-economic contexts characterized by a high level of corruption may end up interpreting corruption as a viable and acceptable practice through which they can overcome the difficulties induced by institutional dimensions (North 1991, 2005; Scott 1995; Urbano and Alvarez 2014). In the light of those considerations, we formulated the following proposition:

Proposition 2. Corruption generally exerts a negative effect on entrepreneurial intentions at an individual level of analysis, whereas this effect is negatively moderated by the quantity of restrictions on entrepreneurial activity imposed by overseeing institutions.

\section{The Influence of National Culture on the Relationship between Corruption and Entrepreneurial Intentions: Interaction across Individual and National Levels of Analysis}

Proposition 2 highlights the complex nature of the relationship between corruption and entrepreneurial intentions. In fact, this relationship seems to be characterized by the presence of a vicious circle that describes and explains the effects of interaction across various levels of analysis. In more detail, many people's broad propensities to adopt corrupt behaviors in order to achieve their entrepreneurial goals could not only root corruption deeper into ordinary entrepreneurial praxis, but it could also affect people's values, beliefs and opinions-that constitute the country's national culture-about the relationship between corruption and entrepreneurship. This process, that starts from individuals and affects the entire country, may disguise another type of interaction in the opposite direction, since it is highly likely that individuals can in turn be influenced by national culture through the well-known mechanism of cultural socialization. In other words, inverse interaction may occur between the country and individual level of analysis, and in conjunction with the process described above (from the individual to the national level of analysis), it may elicit a self-sustaining process that aims to reinforce both corruption and the values, beliefs and opinions of national cultures that facilitate the acceptance of corrupt behaviors right and useful.

Since national values, beliefs and opinions compatible with people's willingness to accept corrupt behaviors can be inter-generationally transmitted through the socialization process, they may increment people's perception of the pervasiveness of corruption in the entrepreneurial ecosystem, reinforcing people's inescapable feeling of being forced to adopt such behavior to succeed in their business 
activities. Finally, sharing such a behavioral model might be at first tolerated and then fully accepted by society, thereby completing and consolidating the vicious circle.

With this in mind, the implementation of national culture theories with the entrepreneurial field of study might be a useful additional tool to unveil the complexity that characterizes the relationship between corruption and entrepreneurial intentions. Thus, national cultures-constituted by shared values, beliefs, attitudes and behavioral habits-seem to play an important role in affecting the relationship between corruption and entrepreneurial behaviors (Hofstede 1980; Husted 1999; Hayton et al. 2002; Taras et al. 2010).

Actually, several studies have explored the relationship between corruption and entrepreneurial behavior through the theoretical framework proposed by Hofstede (1980), who defines national culture as a particular state of mind that differentiates one human group from another (Taras et al. 2010). Hofstede's $(1980,2001)$ original theoretical model states that national culture can be analyzed through four dimensions:

- Individualism/collectivism (IND): This dimension refers to the extent people tend to act as individuals or as members of a community. In other words, this dimension investigates whether people base their decisions on their personal needs or on the needs of their group.

- Power distance (PD): this dimension refers to the extent to which people accept, within a country, that economic or political power is assigned unequally.

- Uncertainty avoidance (UA): this dimension refers to the extent to which a specific society feels threatened by ambiguous situations and tends to reduce the occurrence of these situations by creating more opportunities for career stability; establishing a lot of formal norms and rules; rejecting abnormal behavior and ideas; believing that there is an absolute truth; and attributing great value to specific expertise.

- Masculinity/femininity (MAS): this dimension refers to how many of the shared cultural values within a country can be associated with an ideal model of masculinity-such as assertiveness, the desire for domination over another person, and economic power, success and competitiveness, rather than being linked to characteristics of an ideal feminine model—such as importance being attributed to friendly relationships and cooperation as a way to achieve economic and physical safety.

Several scholars have verified that these cultural dimensions can have a significant impact on individuals' evaluations and perceptions of the behaviors performed by social actors and the various aspects of the regulative dimension (Getz and Volkema 2001; Husted 1999; Davis and Ruhe 2003; Taras et al. 2010).

Studies on the topic of the relationship between national culture and corruption in the entrepreneurial ecosystem have underlined that:

- National cultures characterized by a low level of individualism predispose the population to a high level of corruption, since they emphasize values associated with putting the well-being of one's own group before following formal norms and rules (Husted 1999; Davis and Ruhe 2003).

- National cultures characterized by a high level of power distance predispose the population to a high level of corruption since managerial and economic decisions are made by bosses at their sole discretion, instead of being based on meritocracy, accountability and responsibility. This situation leads people to become obsequious and show formal respect to these bosses, who might base their decisions on corruption or nepotism (Husted 1999; Davis and Ruhe 2003; Getz and Volkema 2001).

- National Cultures characterized by high levels of uncertainty avoidance may predispose the population to a high level of corruption since there are shared values and beliefs that corruption can be an effective tool to reduce the risks and ambiguity related to entrepreneurial activities, providing entrepreneurs with undeserved success (Husted 1999; Getz and Volkema 2001).

- National cultures characterized by a high level of Masculinity predispose the population to higher levels of corruption since they transmit shared values that view corruption as a means justified by 
the ultimate end. For example, people may display a high degree of tolerance towards ethically controversial activities that facilitate the satisfaction of entrepreneurs' desires for success. (Husted 1999; Davis and Ruhe 2003).

The relationship between individualism and corruption seems to be the most controversial. Although Davis and Ruhe (2003) found a reasonably negative relationship between high scores in individualism and the perception of corruption, Husted (1999) provided results that do not confirm that individualism has an actual role in influencing corruption.

Taras et al., in a meta-analysis (Taras et al. 2010), explored the effects on a national level of analysis that the cultural dimensions of the Hofstede model may have on corruption. The results revealed that IND is a negative antecedent of corruption, confirming the work of Davis and Ruhe (2003), whereas PD, UA and MAS appeared as positive antecedents of corruption perception within the entrepreneurial ecosystem (Taras et al. 2010).

Taking into account the work of Taras et al. (2010), one could firmly argue that national culture, subdivided into the four cultural dimensions proposed by Hofstede $(1980,2001)$, has a role in shaping the ways corruption is perceived and carried out by economic agents within a specific entrepreneurial ecosystem.

The fact that countries with a national culture characterized by high levels of PD, UA and MAS and low levels of IND predispose the population to higher levels of corruption could be seen and explained by the vicious circle model described above. More specifically, individuals who operate within an entrepreneurial ecosystem characterized by national culture values compatible with corruption and who recognize these characteristics as belonging to their own entrepreneurial ecosystem may tend to conceive corruption as a useful tool and as useful leverage, and might lead them to achieve their entrepreneurial success and goals more easily, if adequately managed.

In light of this, individuals might operate in tacit compliance with a socially-shared behavioral model marked by corruption. This model would be inter-generationally transmitted, and perceived as unsurprising, shareable and useful, thanks to the well-known psychological mechanism of psychological justifications (Welsh et al. 2014). This mechanism describes a translation from individual perceptions about corruption pervasiveness to actual corrupt behaviors. A corrupted country-characterized by a high frequency of corrupt behaviors-might reinforce perceptions of corruption's pervasiveness that in turn elicit more corrupt behaviors (Rosid et al. 2018). This can be especially true in economies traditionally characterized by high levels of corruption in the past, since it can be considered reasonable to think that people have adapted corrupt behaviors into their business daily activities. From this point of view, it is possible to expect that a would-be entrepreneurs will show higher entrepreneurial intentions if their perceptions of the pervasiveness of corruption in the entrepreneurial ecosystem are "syntonic" with the real level of corruption of the entrepreneurial ecosystem.

On the other hand, in a country traditionally characterized by low level of corruption, individual perceptions that view corruption as pervasive of the entrepreneurial ecosystem may lower business-related behavioral intentions since people are not used to it and may end up discouraged since it rips the entrepreneurial ecosystem from its equity. Hence, it is possible to expect that would-be entrepreneurs show lower entrepreneurial intentions if their perceptions of the pervasiveness of corruption in the entrepreneurial ecosystem are "dystonic" with the real level of corruption of the entrepreneurial ecosystem.

This proposition - if empirically verified-might represent an advancement in the studies about the relationship between the corruption of an entrepreneurial ecosystem and entrepreneurial intentions. Corruption might have multiple direct and side effects on the actual state of the economy of a country, as it might be detrimental to entrepreneurial ecosystems, since a talented would-be entrepreneur could be discouraged from undertaking entrepreneurial activities as a consequence of the dystonia between his own perception of corruption of entrepreneurial ecosystem and the real level of corruption of the entrepreneurial ecosystem. In light of the proposition described above, we want to highlight that environmental perceptions and actual behaviors are strictly related in the corruption domain. 
On a larger scale, it is possible to imagine how individual perceptions of corruption may have qualitatively different impacts on individual entrepreneurial intentions because of the pervasiveness of corruption within the entrepreneurial ecosystem in which the individual operates.

From the above considerations, we formulated a further proposition (Figure 1).

- _ - - High degree of corruption of entrepreneurial ecosystem at the national level Low degree of corruption of entrepreneurial ecosystem at the national level

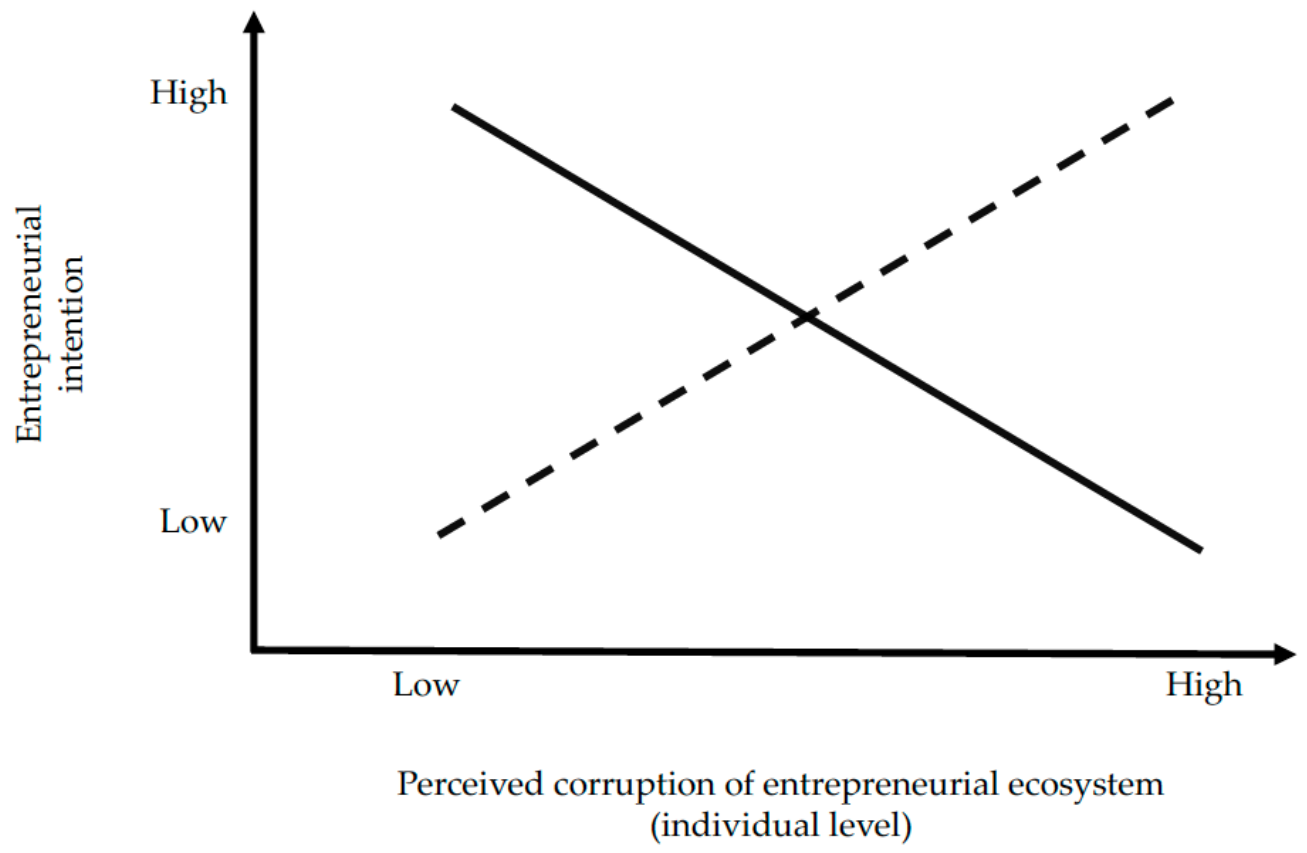

Figure 1. Graphical representation of Proposition 3.

Proposition 3. The relationship between the level of corruption in an entrepreneurial ecosystem, measured at a national level, and the entrepreneurial intentions, are positively moderated by the individual perceptions of the pervasiveness of corruption in the entrepreneurial ecosystem.

\section{Discussion}

The studies carried out to explore the relationship between corruption and entrepreneurial intentions have produced controversial results. From the analysis of the literature, it seems the interaction of these two constructs is influenced by contextual factors both at individual and national levels of analysis. Although the idea that corruption produces a sand-the-wheel effect on entrepreneurial intentions is frequently explored, other studies have underlined that corruption might have a grease-the-wheel effect on entrepreneurial intentions in entrepreneurial ecosystems with pervasive corruption.

Moreover, it is worth noting that the dynamic relationship between corruption and entrepreneurial intentions remains the same both on the individual and national levels of analysis.

It also seems useful to discuss, briefly, the implications of an eventual verification of Proposition 3. In fact, the empirical verification of these two propositions could give birth to a theoretical model deemed finalistic, deterministic and reductionist. Such a model would predict that countries with a national culture characterized by a specific configuration of cultural values-such as high levels of PD, UA and MAS, and a low level of IND—would seem to be forced to develop and sustain corruption inextricably, as a sort of destiny and judicial sentence from which individuals can never escape, due to 
the stability of the national culture over time (Davis and Ruhe 2003; Getz and Volkema 2001). With the purpose of clarifying this important point, it seems useful to make a reference to the slippery slope effect. According to this effect, small but continuous immoral acts may lead individuals to commit ever-greater immoral acts without suffering from repercussions to the self or positive self-perception. In fact, through a gradual process of moral disengagement, individuals avoid seeing themselves in a negative light as unethical people; thus, they are able avoid a sense of cognitive dissonance and maintain a positive vision of themselves (Milgram 1963; Freedman and Fraser 1966; Welsh et al. 2014; Bandura 1999; Mazar et al. 2008; Festinger 1957; Stone and Cooper 2001).

The Slippery Slope Phenomenon: The Effect of Corruption on Entrepreneurial Intentions at the Intra-Individual Level of Analysis

Referring to the socio-cognitive theory of Bandura (1986), many scholars have demonstrated how even individuals who perceive themselves as morally engaged might end up unconsciously carrying out unethical behaviors, even of significant consequence, if these behaviors are enacted gradually over time and not suddenly. This gradualness will lead individuals to experience a slight, but concrete escalation that in turn will drive them away from their initial shared moral models (Welsh et al. 2014).

Taking into account this phenomenon, we can wonder whether individuals who operate in countries characterized by national cultural values that predispose the population to corruption might be exposed precociously and frequently to slippery-slope conditions, and which may lead them to develop unethical behavior because of the cumulative effect of minor transgressions that become major ones (Welsh et al. 2014). The socio-cognitive theory proposed by Bandura (1986) underlines that every conduct or behavior can be learnt through a vicarious learning experience, such that people adopt specific behavioral models simply by seeing other individuals performing them. Therefore, morally engaged individuals may learn and adopt corrupt conduct because of one such a vicarious learning process, initially focused on minor transgressions or small infractions, and then on more serious ones. As this process will continue gradually, it will not clash with the moral and ethical sense of self of these initially morally-engaged individuals (Welsh et al. 2014).

In light of these considerations, we can argue that a national culture marked by endemic corruption would not form corrupt individuals directly, but it could provide the intellectual tools, habits, ways of thinking and values that may end up accelerating and promoting the adoption of a corporate managerial style based on corruption. Entrepreneurs could see corruption as a useful tool to be used in their business activities (Husted 1999).

\section{Conclusions and Limitations}

The main limitation of this paper is represented by the fact that the propositions were not verified through empirical research. However, if our propositions are confirmed, it will be necessary to revise the theoretical models that affirm the existence of a linear relationship between corruption and the entrepreneurial ecosystem; that is, a relationship that is unaffected by contextual elements peculiar to a given country, such as the ones cited above as "sand-the-wheel" and "grease-the-wheel". If that is so, prompted by the awareness that corrupt phenomena acquire a specific cultural valence in relationship to differences in national cultures, governments should partially redesign their anti-corruption policies. We can argue that they should shift their focus from a logic centered on fighting corruption directly to a logic of prevention, concentrating on developing strategies that can act simultaneously both on the individual level and on the national level. More specifically, in a country with a high degree of perception of corruption, counteractions aimed at making people more aware of the pervasiveness of corruption within their entrepreneurial ecosystem could paradoxically produce counterproductive effects, since it would confirm people's belief that entrepreneurs must come to terms with an endemic entrepreneurial ecosystem that is both corrupt and corrupting.

In conclusion, it appears possible to imagine and implement effective public policies aimed at improving the entrepreneurial ecosystem in countries with a high level of corruption only by taking 
into account the great complexity of the relationship between corruption and entrepreneurial intentions within that country.

Author Contributions: These authors contributed equally to this work.

Funding: This research received no external funding.

Conflicts of Interest: The authors declare no conflicts of interest.

\section{References}

Acs, Zoltan J., Erik Stam, David B. Audretsch, and Allan O'Connor. 2017. The lineages of the entrepreneurial ecosystem approach. Small Business Economics 49: 1-10. [CrossRef]

Aidis, Ruta, Saul Estrin, and Tomasz Marek Mickiewicz. 2012. Size matters: Entrepreneurial entry and government. Small Business Economics 39: 119-39. [CrossRef]

Ajzen, Icek. 1991. The theory of planned behavior. Organizational Behavior and Human Decision Processes 50: 179-211. [CrossRef]

Allini, Alessandra, Luca Ferri, Marco Maffei, and Annamaria Zampella. 2017. The Effect of Perceived Corruption on Entrepreneurial Intention: Evidence from Italy. International Business Research 10: 75-86. [CrossRef]

Alvedalen, Janna, and Ron Boschma. 2017. A critical review of entrepreneurial ecosystems research: Towards a future research agenda. European Planning Studies 25: 887-903. [CrossRef]

Andersen, Henrik, and Jochen Mayerl. 2017. Social desirability and undesirability effects on survey response latencies. Bulletin of Sociological Methodology/Bulletin de Méthodologie Sociologique 135: 68-89. [CrossRef]

Anokhin, Sergey, and William S. Schulze. 2009. Entrepreneurship, innovation, and corruption. Journal of Business Venturing 24: 465-76. [CrossRef]

Aparicio, Sebastian, David Urbano, and David Audretsch. 2016. Institutional factors, opportunity entrepreneurship and economic growth: Panel data evidence. Technological Forecasting and Social Change 102: 45-61. [CrossRef]

Armantier, Olivier, and Amadou Boly. 2008. Can Corruption Be Studied in the Lab? Comparing a Field and a Lab Experiment. Montreal: CIRANO-Scientific Publications.

Arranz, N., M. F. Arroyabe, and J. C. Fdez. de Arroyabe. 2019. Entrepreneurial intention and obstacles of undergraduate students: the case of the universities of Andalusia. Studies in Higher Education 44: 2011-24. [CrossRef]

Ashforth, Blake E., Dennis Gioia, Sandra L. Robinson, and Linda K. Trevino. 2008. Re-viewing organizational corruption. Academy of Management Review 33: 670-84. [CrossRef]

Autio, Erkko, Robert H. Keeley, Magnus Klofsten, George G. C. Parker, and Michael G. Hay. 2001. Entrepreneurial intent among students in Scandinavia and in the USA. Enterprise and Innovation Management Studies 2: 145-60. [CrossRef]

Bandura, Albert. 1986. Social Foundations of Thought and Action: A Social Cognitive Theory. Englewood Cliffs: Prentice-Hall, Inc.

Bandura, Albert. 1999. Moral disengagement in the perpetration of inhumanities. Personality and Social Psychology Review 3: 193-209. [CrossRef] [PubMed]

Bardhan, Pranab. 1997. Corruption and development: a review of issues. Journal of Economic Literature 35: 1320-46.

Barr, Abigail, and Danila Serra. 2010. Corruption and culture: An experimental analysis. Journal of Public Economics 94: 862-69. [CrossRef]

Bell, Robin. 2019. Predicting entrepreneurial intention across the university. Education and Training 61: 815-31. [CrossRef]

Brown, Ross, and Suzanne Mawson. 2019. Entrepreneurial ecosystems and public policy in action: A critique of the latest industrial policy blockbuster. Cambridge Journal of Regions, Economy and Society. [CrossRef]

Ceresia, Francesco. 2018. The Role of Entrepreneurship Education in Fostering Entrepreneurial Intentions and Performances: A Review of 30 Years of Research. Equidad y Desarrollo 31: 47-66. [CrossRef]

Ceresia, Francesco, and Claudio Mendola. 2019. Entrepreneurial Self-Identity, Perceived Corruption, Exogenous and Endogenous Obstacles as Antecedents of Entrepreneurial Intention in Italy. Social Science 8: 54. [CrossRef]

Choo, Stephen, and Melvin Wong. 2006. Entrepreneurial intention: Triggers and barriers to new venture creations in Singapore. Singapore Management Review 28: 47-64. 
Ciziceno, Marco, and Giovanni A. Travaglino. 2019. Perceived corruption and individuals' life satisfaction: The mediating role of institutional trust. Social Indicators Research 141: 685-701. [CrossRef]

Davis, James H., and John A. Ruhe. 2003. Perceptions of country corruption: Antecedents and outcomes. Journal of Business Ethics 43: 275-88. [CrossRef]

del Mar Salinas-Jiménez, M., and Javier Salinas-Jiménez. 2007. Corruption, efficiency and productivity in OECD countries. Journal of Policy Modeling 29: 903-15. [CrossRef]

Djankov, Simeon, Edward Miguel, Yingyi Qian, Gèrard Roland, and Ekaterina Zhuravskaya. 2005. Who are Russia's entrepreneurs? Journal of the European Economic Association 3: 587-97. [CrossRef]

Dreher, Alex, and Martin Gassebner. 2013. Greasing the wheels? The impact of regulations and corruption on firm entry. Public Choice 155: 413-32. [CrossRef]

Drnovšek, Mateja, Joakim Wincent, and Melissa S. Cardon. 2010. Entrepreneurial self-efficacy and business start-up: developing a multi-dimensional definition. International Journal of Entrepreneurial Behavior and Research 16: 329-48. [CrossRef]

Dutta, Nabamita, and Russell Sobel. 2016. Does corruption ever help entrepreneurship? Small Business Economics 47: 179-99. [CrossRef]

Engle, Robert L., Nikolay Dimitriadi, Jose V. Gavidia, Christofer Schlaegel, Servane Delanoe, Irene Alvarado, Xiaohong He, Samuel Buame, and Birgitta Wolff. 2010. Entrepreneurial intent: A twelve-country evaluation of Ajzen's model of planned behavior. International Journal of Entrepreneurial Behavior and Research 16: 35-57. [CrossRef]

Esfandiar, Kourosh, Mohamad Sharifi-Tehrani, Stephen Pratt, and Levent Altinay. 2019. Understanding entrepreneurial intentions: A developed integrated structural model approach. Journal of Business Research 94: 172-82. [CrossRef]

Faggian, Alessandra, Mark Partridge, and Edward J. Malecki. 2017. Creating an environment for economic growth: creativity, entrepreneurship or human capital? International Journal of Urban and Regional Research 41: 997-1009. [CrossRef]

Festinger, Leon. 1957. A Theory of Cognitive Dissonance. Stanford: Stanford University.

Freedman, Jonathan L., and Scott C. Fraser. 1966. Compliance without pressure: the foot-in-the-door technique. Journal of Personality and Social Psychology 4: 195-202. [CrossRef]

Gang, Xu, and Go Yano. 2017. How does anti-corruption affect corporate innovation? Evidence from recent anti-corruption efforts in China. Journal of Comparative Economics 45: 498-519.

Getz, Kathleen A., and Roger J. Volkema. 2001. Culture, perceived corruption, and economics: A model of predictors and outcomes. Business and Society 40: 7-30. [CrossRef]

Gilmartin, Shannon K., Marissa E. Thompson, Emily Morton, Qu Jin, Helen L. Chen, Anne Colby, and Sheri D. Sheppard. 2019. Entrepreneurial intent of engineering and business undergraduate students. Journal of Engineering Education 108: 316-36. [CrossRef]

Glaeser, Edward L., and Raven E. Saks. 2006. Corruption in America. Journal of Public Economics 90: $1053-72$. [CrossRef]

Hanoteau, Julien, and Virginie Vial. 2014. Grease or Sand the Wheel? The Effect of Individual Bribes on the Drivers of Aggregate Productivity Growth. Journal of Indonesian Economy and Business 29: 1-16. [CrossRef]

Harbi, Sana E., and Alistair R. Anderson. 2010. Institutions and the shaping of different forms of entrepreneurship. Journal of Socio-Economics 39: 436-44. [CrossRef]

Hayton, James C., Gerard George, and Shaker A. Zahra. 2002. National culture and entrepreneurship: A review of behavioral research. Entrepreneurship Theory and Practice 26: 33-52. [CrossRef]

Heider, Fritz. 1946. Attitudes and cognitive organization. The Journal of Psychology 21: 107-12. [CrossRef]

Hofstede, Geert. 1980. Culture's Consequences: International Differences in Work-Related Values. Beverly Hills: Sage Publications, Inc.

Hofstede, Geert. 2001. Culture's Consequences: Comparing Values, Behaviors, Institutions and Organizations across Nations, 2nd ed. Thousand Oaks: Sage Publications.

Holcombe, Randall G. 1998. Entrepreneurship and economic growth. The Quarterly Journal of Austrian Economics 1: 45-62. [CrossRef]

Husted, Bryan W. 1999. Wealth, culture, and corruption. Journal of International Business Studies 30: 339-59. [CrossRef] 
Jancsics, David. 2019. Corruption as resource transfer: An interdisciplinary synthesis. Public Administration Review 79: 1-15. [CrossRef]

Johnson, Timoty P., and Fons J. Van de Vijver. 2003. Social desirability in cross-cultural research. Cross-Cultural Survey Methods 325: 195-204.

Kuckertz, Andreas. 2019. Let's take the entrepreneurial ecosystem metaphor seriously! Journal of Business Venturing Insights 11: e00124. [CrossRef]

Levitt, Steven D., and John A. List. 2007. What do laboratory experiments measuring social preferences reveal about the real world? Journal of Economic Perspectives 21: 153-74. [CrossRef]

$\mathrm{Li}$, Shaomin, and Jun Wu. 2010. Why some countries thrive despite corruption: The role of trust in the corruption-efficiency relationship. Review of International Political Economy 17: 129-54. [CrossRef]

Linan, Francisco, and Yi W. Chen. 2009. Development and Cross-Cultural application of a specific instrument to measure entrepreneurial intentions. Entrepreneurship Theory and Practice 33: 593-617. [CrossRef]

Lucas, David S., and Caleb S. Fuller. 2017. Entrepreneurship: Productive, unproductive, and destructive-Relative to what? Journal of Business Venturing Insights 7: 45-49. [CrossRef]

Mauro, Paolo. 1995. Corruption and growth. The Quarterly Journal of Economics 110: 681-712. [CrossRef]

Mazar, Nina, On Amir, and Dan Ariely. 2008. The dishonesty of honest people: A theory of self-concept maintenance. Journal of Marketing Research 45: 633-44. [CrossRef]

Milgram, Stanley. 1963. Behavioral study of obedience. The Journal of Abnormal and Social Psychology 67: 371-78. [CrossRef]

Moiseev, V. V., and I. V. Goncharova. 2019. Corruption in Russia: Reasons for the Growth. Paper presented at 2019 5th International Conference on Social Science and Higher Education (ICSSHE 2019), Xiamen, China, August 23-25.

Moreno, Alejandro. 2002. Corruption and democracy: A cultural assessment. Comparative Sociology 1: 495-507. [CrossRef]

Neneh, Brownhilder N. 2014. An assessment of entrepreneurial intention among university students in Cameroon. Mediterranean Journal of Social Sciences 5: 542-52. [CrossRef]

North, Douglass C. 1991. Institutions. Journal of Economic Perspectives 5: 97-112. [CrossRef]

North, Douglass C. 2005. Understanding the Process of Economic Change. Princeton: Princeton University Press.

Olken, Benjamin A. 2009. Corruption perceptions vs. corruption reality. Journal of Public Economics 93: 950-64. [CrossRef]

Orr, Ryan J., and W. Richard Scott. 2008. Institutional exceptions on global projects: A process model. Journal of International Business Studies 39: 562-88. [CrossRef]

Paunov, Caroline. 2016. Corruption's asymmetric impacts on firm innovation. Journal of Development Economics 118: 216-31. [CrossRef]

Pertiwi, Kanti. 2018. Contextualizing Corruption: A Cross-Disciplinary Approach to Studying Corruption in Organizations. Administrative Sciences 8: 12. [CrossRef]

Rosid, Arifin, Chris Evans, and Binh Tran-Nam. 2018. Perceptions of Corruption and Tax Non-Compliance Behaviour: Policy Implications for Developing Countries. Bullettin of Indonesian Economic Studies 54: 25-60. [CrossRef]

Samila, Sampsa, and Olav Sorenson. 2011. Venture capital, entrepreneurship, and economic growth. The Review of Economics and Statistics 93: 338-49. [CrossRef]

Scott, W. Richard. 1995. Institutions and Organizations. Thousand Oaks: Sage.

Shwetzer, Claudia, Alex Maritz, and Quan Nguyen. 2019. Entrepreneurial ecosystems: A holistic and dynamic approach. Journal of Industry-University Collaboration 1: 79-95. [CrossRef]

Singh, Shiwangi, Shuchi Sinha, Vellupillai M. Das, and Anuj Sharma. 2019. A framework for linking entrepreneurial ecosystem with institutional factors: A modified total interpretive structural modelling approach. Journal for Global Business Advancement 12: 382-404.

Stam, Erik. 2015. Entrepreneurial ecosystems and regional policy: a sympathetic critique. European Planning Studies 23: 1759-769. [CrossRef]

Stam, Erik. 2018. Measuring entrepreneurial ecosystems. In Entrepreneurial Ecosystems. New York: Springer, pp. 173-97.

Stam, Erik, and Ben Spigel. 2016. Entrepreneurial ecosystems. USE Discussion Paper Series 16. Available online: https://ideas.repec.org/p/use/tkiwps/1613.html (accessed on 25 June 2018). 
Stenholm, Pekka, Zoltan J. Acs, and Robert Wuebker. 2013. Exploring country-level institutional arrangements on the rate and type of entrepreneurial activity. Journal of Business Venturing 28: 176-93. [CrossRef]

Stone, Jeff, and Joel Cooper. 2001. A self-standards model of cognitive dissonance. Journal of Experimental Social Psychology 37: 228-43. [CrossRef]

Swann, William B., Jr. 1983. Self-verification: Bringing social reality into harmony with the self. Social Psychological Perspectives on the Self 2: 33-66.

Szerb, László, Esteben Lafuente, Krisztina Horváth, and Balàzs Páger. 2019. The relevance of quantity and quality entrepreneurship for regional performance: The moderating role of the entrepreneurial ecosystem. Regional Studies 53: 1308-320. [CrossRef]

Taras, Vas, Bradley L. Kirkman, and Pier Steel. 2010. Examining the impact of culture's consequences: A three-decade, multilevel, meta-analytic review of Hofstede's cultural value dimensions. Journal of Applied Psychology 95: 405-39. [CrossRef]

Thornton, Patricia H., Doming Ribeiro-Soriano, and David Urbano. 2011. Socio-cultural factors and entrepreneurial activity: An overview. International Small Business Journal 29: 105-18. [CrossRef]

Transparency International. 2017. Corruption Perception Index. Available online: www.transparency.org (accessed on 25 June 2018).

Urbano, David, and Claudia Alvarez. 2014. Institutional dimensions and entrepreneurial activity: An international study. Small Business Economics 42: 703-16. [CrossRef]

Wang, Chengchun, Yiping Liu, and Norbert Mundorf. 2019. Regional differences in entrepreneurial intention of college students may exacerbate regional economic gap. Journal of Entrepreneurship Education 22: 1-11.

Ward, Alexander, Brizeida Hernández-Sánchez, and Jose C. Sánchez-García. 2019. Entrepreneurial Intentions in Students from a Trans-National Perspective. Administrative Sciences 9: 37. [CrossRef]

Welsh, David T., Lisa D. Ordóñez, Deirdre G. Snyder, and Michael S. Christian. 2014. The slippery slope: How small ethical transgressions pave the way for larger future transgressions. Journal of Applied Psychology. [CrossRef] [PubMed]

Wennekers, Sander, and Roy Thurik. 1999. Linking entrepreneurship and economic growth. Small Business Economics 13: 27-56. [CrossRef]

World Bank. 2016. Worldwide Governance Indicators. Available online: https://datamarket.com/data/set/16uz/ control-of-corruptionestimate\#!ds=16uz!i75=5qanddisplay=table (accessed on 27 June 2018).

Zakharov, Nikita. 2019. Does corruption hinder investment? Evidence from Russian regions. European Journal of Political Economy 56: 39-61. [CrossRef]

Zhou, Jessie Q., and Mike W. Peng. 2012. Does bribery help or hurt firm growth around the world? Asia Pacific Journal of Management 29: 907-21. [CrossRef] 